\title{
Práticas não adequadas nos tribunais de contas
}

\section{André Feliciano Lino ${ }^{1}$}

\section{André Carlos Busanelli de Aquino ${ }^{2}$}

${ }^{1}$ Universidade Federal do Pará / Faculdade de Ciências Contábeis, Belém / PA - Brasil

${ }^{2}$ Universidade de São Paulo / Faculdade de Economia, Administração e Contabilidade de Ribeirão Preto, Ribeirão Preto / SP - Brasil

\begin{abstract}
Os tribunais de contas brasileiros como organizações de auditoria governamental têm sido historicamente questionados pela continua revelação de práticas socialmente contestadas atribuídas aos conselheiros. Este artigo analisa a manutenção dessas más práticas (organizational wrongdoing), sustentadas e apoiadas pela atuação de conselheiros, assessores, diretores de auditoria e apoiadores do escalão técnico, os quais detém maior influência e poder em uma organização tipicamente permeada por lógicas institucionais incompatíveis e conflitantes. Utilizou-se o caso do Tribunal de Contas do Estado do Rio de Janeiro para analisar as práticas ilegítimas largamente utilizadas que se tornaram públicas recentemente. O caso foi analisado em uma abordagem qualitativa, a partir de entrevistas (com auditores e conselheiros da organização) trianguladas com documentos públicos. A análise conclui que a lógica institucional elite-patrimonialista que opera naquela organização induziu o amplo uso de más práticas naquele tribunal, as quais foram legitimadas por estratégias de poder (episódico e sistêmico) e por trocas recíprocas em todos os níveis organizacionais. Ainda, a análise identificou más práticas de suporte que surgem ao longo da hierarquia, operadas sob influência de poder sistêmico em geral, que são desdobramentos de estratégias para sustentar as más práticas embrionárias.
\end{abstract}

Palavras-chave: lógicas institucionais; práticas não adequadas; tribunais de contas; corrupção.

\section{Prácticas inadecuadas en los tribunales de cuentas}

Históricamente, los tribunales de cuentas brasileños como organizaciones de auditoría del gobierno han sido cuestionados por la divulgación continua de prácticas socialmente censuradas atribuidas a los consejeros. Este artículo analiza el mantenimiento de esas malas prácticas (organizational wrongdoing), sostenidas y respaldadas por las acciones de consejeros, asesores, directores de auditoría y miembros del cuerpo técnico de auditoría, que tienen una mayor influencia y poder en una organización típicamente impregnada de lógicas institucionales incompatibles y conflictivas. Se utilizó el caso del Tribunal de Cuentas del Estado de Río de Janeiro para analizar las prácticas ilegítimas ampliamente utilizadas que recientemente se han hecho públicas. El caso fue analizado desde un enfoque cualitativo, basado en entrevistas (con auditores y consejeros de la organización) trianguladas con documentos públicos. El análisis concluye que la lógica institucional de élite patrimonialista que opera en esa organización indujo al uso generalizado de prácticas inapropiadas en esa corte, que fueron legitimadas por estrategias de poder (episódico y sistémico) y por intercambios recíprocos en todos los niveles organizacionales. Aun, el análisis identificó malas prácticas de soporte que surgen a lo largo de la jerarquía, operadas bajo la influencia del poder sistémico en general, que son estrategias que se desarrollan para sostener malas prácticas embrionarias. Palabra clave: lógica institucional; prácticas inapropiadas; tribunales de cuentas; corrupción.

\section{Organizational wrongdoing in courts of accounts}

Historically, the Brazilian Courts of Accounts have been questioned over the frequent misconduct of magistrates. This article analyzed how organizational wrongdoing is sustained and preserved by magistrates, their cabinet members, audit directors and technical body members, who hold influence and power in this type of organization typically permeated by multiple incompatible and conflicting institutional logics. The case of the Rio de Janeiro State Court of Accounts was analyzed to discover the socially illegitimate practices widely adopted in the organization and which recently became public. A qualitative approach was used based on interviews (with auditors and magistrates) and public documents. The analysis indicates that an elite-patrimonial institutional logic was operating at the Rio de Janeiro State Court of Accounts, which induced organizational wrongdoing, based on the use of episodic and systemic power strategies and reciprocity norms. Finally, the findings point out that supportive wrongdoing is seen in the hierarchy, operating under the influence of systemic power in general, applied to sustain the embryonic strategies of wrongdoing. Keywords: organizational wrongdoing; courts of accounts; institutional logic; corruption. 


\section{INTRODUÇÃO}

Escândalos recentes têm direcionado a atenção da população e da academia a diversos casos de más práticas organizacionais. Tais práticas ilegítimas e inadequadas ocorrem tanto no setor público quanto no privado e, por vezes, envolvem mais de uma organização. Exemplos são os benefícios em contratos de direito de exibição de competições da Federação Internacional de Futebol (Fédération Internationale de Football Association [FIFA]) (Sugden \& Tomlinson, 2017), a suposta compra do silêncio de um hacker pela Uber para esconder o vazamento de dados de clientes (CBS, 2019), a provável adulteração de produtos por empresas como a JBS, o conflito de interesses na atuação do Conselho de Administração de Recursos Fiscais (CARF), além dos casos de corrupção envolvendo empreiteiras e estatais que vieram à tona, respectivamente, por meio das operações Carne-Fraca, Zelotes e Lava Jato (Arantes, Gusmão, \& Costa, 2019). Além disso, no caso da Operação Lava Jato, as práticas empregadas pela força tarefa nas fases de investigação e julgamento têm sido questionadas (Intercept Brasil, 2019).

Um ponto comum das más práticas organizacionais é a ocorrência de violação de leis, códigos profissionais ou princípios éticos quando indivíduos trabalham para atingir seus objetivos - sejam próprios ou organizacionais. Tais casos são analisados na literatura de más práticas organizacionais (no inglês organizational wrongdoing ou organizational misconduct) (Greve, Palmer, \& Pozner, 2010; Palmer, 2017; Palmer, Smith-Crowe, \& Greenwood, 2016). Essa literatura avançou consideravelmente na discussão das causas dessas práticas no nível individual de análise e das consequências para organização como um todo (Palmer, 2017; Palmer et al., 2016). A ocorrência dessas más práticas deixou de ser vista como algo atípico, sendo vista como algo mais recorrente. As más práticas seriam decorrentes e associadas às mesmas estruturas, artefatos e processos desenhados para ganho de eficiência, como as estruturas de poder formal hierarquizadas (Palmer, 2013). Os tribunais de contas são um exemplo de organização recorrentemente associada a más práticas no Brasil. Já em 2009 o trabalho de Loureiro, Teixeira, e Moraes (2009) aponta as conexões político-partidárias existentes em seus postos de comando. Mais recentemente, Teixeira (2017) trouxe diversas evidências de práticas inadequadas, como formação de quadrilha, corrupção ativa, fraudes em licitações e recebimentos de propina, exercidas por membros dessas organizações.

Práticas organizacionais (adequadas ou inadequadas) estão imbricadas e são indissociáveis do fluxo de processos, rotinas, normas e crenças organizacionais (Jarzabkowski, Balogun, \& Seidl, 2007; Lounsbury, 2008; Thornton, Ocasio, \& Lounsbury, 2012). Portanto, a presença e recorrência dessas práticas pode ser analisada pela influência das lógicas institucionais presentes na organização. Tais lógicas institucionais são frameworks cognitivos, historicamente constituídos, que definem o comportamento de atores organizacionais (Thornton et al., 2012).

Tomando por exemplo o caso da Arthur Andersen, a introdução de uma lógica corporativa sobreposta à antiga lógica profissional (ou fiduciária) parece ter levado os membros da empresa de auditoria às más práticas, que eventualmente a conduziram à condenação (Palmer, 2017; Thornton et al., 2012). No caso dos tribunais de contas, estudos anteriores indicam a existência de duas lógicas institucionais sobrepostas, a lógica técnico-profissional e a lógica elite-patrimonialista (Lino, 2019). Enquanto a lógica técnico-profissional prioriza a impessoalidade e o bem público, a lógica elitepatrimonialista se baseia em barganhas visando o benefício de um grupo específico.

Como mencionado, o foco da literatura tem sido na identificação de causas de más práticas em organizações, o que pode explicar a ausência de estudos sobre como e porque tais práticas se mantêm ao longo do tempo (Palmer et al., 2016). Este artigo sugere que as más práticas não ocorreriam em 
uma organização apenas pelas características individuais dos líderes ou por sua estrutura formal de distribuição de poder, mas sobretudo pela estrutura institucional, ou seja, pelas lógicas institucionais que sustentarão tais práticas internamente.

No caso dos tribunais de contas, uma lógica caraterizada como elite-patrimonialista está associada a diversas más práticas (Lino, 2019). A lógica institucional não guia apenas o comportamento de atores em postos de comando nas organizações, mas por meio do exercício de poder dos mesmos também afeta o desenho dos processos e a rotinização das práticas internas (Battilana, 2006; Zald \& Lounsbury, 2010). Na camada superior dos tribunais de contas há atores com maior poder no que se refere a direitos de decisão e distribuição de recursos dentro da organização, como os conselheiros, passando por secretários gerais, diretores e, finalmente, auditores - que seriam os atores com menor poder (Lino, 2019; Moreira \& Vieira, 2003). Quanto maior o poder relativo de um grupo de atores em postos de comando, maior a possibilidade de que a lógica institucional que eles suportam seja a lógica dominante em uma organização (Besharov \& Smith, 2014). Dessa maneira, atores com maior poder com acesso a recursos relacionais e materiais (Lawrence, 2008) desenham deliberada e estrategicamente elementos da estrutura organizacional em benefício próprio (Battilana, 2006; Lawrence \& Suddaby, 2006), reduzindo a atuação das outras lógicas institucionais competidoras. Portanto, o desbalanceamento de poder entre atores que suportam (e são guiados) por determinadas lógicas acomodaria internamente as lógicas conflitantes ao longo da cadeia hierárquica, provavelmente em prol da manutenção da lógica que interessa ao grupo no poder (Spence \& Carter, 2014). No caso, a lógica que interessa ao grupo no poder seria a elite-patrimonialista, o que sustentaria as más práticas identificadas.

Este artigo busca aprofundar as explicações sobre a ocorrência e sustentação de más práticas nos tribunais de contas e analisa as estratégias utilizadas por indivíduos com maior poder na organização para manter as más práticas organizacionais em curso. Esses indivíduos aqui denominados de "atores com maior poder" são aqueles com acesso facilitado a recursos relacionais e materiais. A pesquisa adotou uma abordagem qualitativa no caso do Tribunal de Contas do Estado do Rio de Janeiro (TCE-RJ). A análise foi baseada em entrevistas e análise de documentos. O caso foi selecionado de acordo com sugestão metodológica de Greve et al. (2010), onde as más práticas organizacionais são um fato empírico observado por agentes de controle na sociedade e não um juízo do pesquisador. No caso em questão, as más práticas organizacionais envolvendo seus Conselheiros foram expostas pelo Ministério Público Federal (MPF) e pela Polícia Federal (PF), em 2017. Segundo o MPF, os conselheiros desse tribunal de contas recebiam um percentual de contratos firmados entre o Governo Estadual e empresas privadas, como forma de propina para relaxarem a fiscalização nesses contratos.

Os resultados apontam que a dinâmica de poder, formal e informalmente estabelecida dentro da organização, foi crucial para que a lógica institucional técnico-profissional voltada à proteção do interesse público fosse silenciada enquanto atores guiados pela lógica elite-patrimonialista executavam estratégias para maximizar ganhos exclusivos desse grupo - o que é definido como imoral (Ashforth \& Lange, 2016) e, muitas vezes, infringe aspectos legais.

\section{HIERARQUIA E PODER COMO FONTE DE MÁS PRÁTICAS ORGANIZACIONAIS}

Más práticas organizacionais podem ser definidas como o comportamento de indivíduos dentro de uma organização que transgrida a linha imaginária que separa o que é certo daquilo que é errado; tal transgressão é avaliada por um agente de controle na sociedade (Greve et al., 2010). O agente de 
controle é definido como um ator que representa uma coletividade e é capaz de impor sanções em nome dessa mesma coletividade (Greve et al., 2010). A linha imaginária entre o que é certo e errado, bem como a coerção do agente de controle, é uma função determinada pelas instituições vigentes considerando leis, códigos profissionais e princípios éticos amplamente aceitos (Palmer, 2017). Em outras palavras, uma má prática organizacional é aquela que não é legítima segundo a avaliação de um agente de controle que atuaria como fonte de legitimidade (Deephouse \& Suchmann, 2008).

Esse comportamento ilegítimo pode envolver transgressão às leis ou utilização de princípios imorais, que são definidos como comportamento autointeressado que, intencionalmente ou não, prejudica terceiros (Ashforth \& Lange, 2016; Greve et al., 2010). Portanto, o que é considerado uma má prática organizacional varia no tempo e no local em que ocorrem, são construídas socialmente e dependem da avaliação de um agente de controle (Palmer, 2017). Por exemplo, no início da Revolução Industrial, as práticas organizacionais associadas ao trabalho infantil e a turnos superiores a 10 horas de trabalho diário eram consideradas adequados. Esse entendimento mudou na maioria das sociedades contemporâneas.

Estudos anteriores indicam que as más práticas em geral começam pelo topo da hierarquia organizacional (Ashforth \& Anand, 2003; Palmer, 2017). Como a autoridade formal (que é uma forma de distribuição de poder) está enraizada na hierarquia de organizações, atores na base da hierarquia e com menos poder são compelidos por seus superiores a aceitar e por vezes participar dessas más práticas (Ashforth \& Anand, 2003; Palmer, 2008). Essa influência pode vir também do fato desses atores em altas posições hierárquicas serem vistos como legítimos (Phillips, Lawrence, \& Hardy, 2004). Por exemplo, os membros do alto escalão ao se engajarem nas más práticas, inadvertidamente autorizam tais práticas nos demais níveis hierárquicos (Ashforth \& Anand, 2003). Os laços típicos de grupos de uma elite social também auxiliam tais atores em posições de poder a criarem oportunidades para a conduta ilegal (Palmer, 2017). Portanto, apesar da autoridade formal ser atribuída e desenhada para diminuir problemas de coordenação e de laços sociais facilitarem trocas econômicas, essas mesmas estruturas sociais, e de poder, que seriam utilizadas para disseminar boas práticas também podem ser utilizadas para gerar más práticas - de modo que essas atividades se tornam rotineiras e dispersas nas organizações (Palmer, 2013).

Poder é um conceito central na literatura sobre más práticas organizacionais. É definido como um fenômeno relacional em que um ator ou grupo (com maior poder) é capaz de alterar as crenças e os comportamentos de outros atores (com menor poder). Essa ação pode ser episódica ou sistêmica (Palmer, 2013; Lawrence, 2008). Formas episódicas de poder são ações discretas de atores específicos na hierarquia com uso de influência ou força - muito embora a última não seja uma tática comum em organizações modernas (Lawrence, 2008; Pfeffer, 1981). A principal diferença entre influência e força é que a primeira afeta o cálculo de custos e benefícios de um ator para realizar determinada ação, enquanto a segunda restringe as ações que podem ser tomadas (Lawrence, Winn, \& Jennings, 2001). Formas de poder sistêmico são impessoais e operam com rotinas e regras - sendo a base para estabilidade de processos nas hierarquias organizacionais (Lawrence, 2008). Exemplo são as regras que distribuem poder e a hierarquia como uma forma legítima de atribuir papéis organizacionais (de maior ou menor poder) (Hardy \& Clegg, 1996; Lowndes \& Roberts, 2013).

Usualmente, atores e grupos com maior poder dentro das organizações têm a capacidade de desenhar as regras e rotinas que são fonte do poder sistêmico, gerando benefícios para eles próprios 
e favorecendo lógicas institucionais preferidas (Battilana, 2006; Kellogg, 2011; Lawrence et al., 2001). Lógicas institucionais são frameworks cognitivos que atuam como guias para as ações nas organizações (Thornton et al., 2012). Porém, não basta o trabalho dos atores com maior poder na criação das regras e rotinas. Um conjunto de atores que não ocupam posições de liderança ou influência (non-elite actors), mas que possuem direitos de decisão e de influência sobre subordinados, diariamente atuam na manutenção das estruturas de poder e das lógicas institucionais existentes na organização (Lawrence, 2008; Lawrence \& Suddaby, 2006).

Em alguma medida tais atores da hierarquia intermediária podem se engajar nas más práticas pela "norma da reciprocidade" (Javor \& Jancsics, 2016; Palmer, 2008). A expectativa de reciprocidade lhes garante "favores", como pagamento por manterem as práticas inadequadas de interesse do grupo de maior poder na organização. Tais favores viriam sob a forma de recursos econômicos, políticos ou culturais (Khan, 2012; Palmer, 2008).

Por vezes, uma mesma organização opera sob a influência de múltiplas lógicas institucionais (Besharov \& Smith, 2014), que podem estar distribuídas em diferentes áreas ou setores da organização (Birkholz, 2015). Tais lógicas tem diferentes graus de compatibilidade e de centralidade na organização; quanto mais compatíveis, mais consistentes entre si e mais se auto reforçarão, e quanto mais centrais, mais serão igualmente válidas e relevantes para o funcionamento da organização (Besharov \& Smith, 2014). Usualmente, as lógicas preferidas pelos atores com maior poder têm preponderância na organização - já que são desenhadas estrategicamente por eles (Zald \& Lounsbury, 2010).

Em relação às áreas ou setores da organização, a especialização das tarefas e competências de atuação alocadas em cada área pode facilitar o surgimento e a manutenção de más práticas. Os atores de uma área podem não ter acesso a informações completas das outras áreas, especialmente se estiverem em níveis hierárquicos distintos (Ashforth \& Anand, 2003; Palmer, 2008). Ainda, atores de uma área podem estar protegidos por segredo industrial, conhecimento estratégico ou outra forma de blindagem. Como diferentes práticas estão associadas a diferentes lógicas, a departamentalização poderia aumentar o efeito negativo da especialização de tarefas, caso diferentes áreas da organização sigam lógicas institucionais incompatíveis no que se refere à execução de boas práticas.

Em resumo, se uma lógica institucional dominante trouxer consigo traços de menosprezo às regras legais e/ou aos limites morais mais frouxos ou amplos, é provável que induza o surgimento de más práticas organizacionais em certas áreas ou trechos da organização (Palmer, 2017). Dependendo do poder relativo dos atores guiados por essa lógica (p. ex., se são atores com maior poder), estes criariam regras e rotinas intraorganizacionais que beneficiariam seu grupo de elite e favoreceriam a lógica institucional de suas preferências (e que induz e facilita aquelas práticas organizacionais).

Portanto, esse grupo utilizaria formas de poder sistêmico e episódico para manter tais práticas (organizational wrongdoing), fortalecendo indiretamente a lógica dominante e mitigando a resistência de lógicas institucionais competidoras (não compatíveis com suas práticas e seus objetivos), mesmo que as lógicas competidoras também sejam centrais para a organização. Por exemplo, segundo Thornton et al. (2012), o desbalanceamento entre lógicas causado pela preponderância da lógica de mercado pode ser uma das raízes das más práticas que levaram à crise global de 2008. Contudo, a discussão de manutenção das práticas inadequadas ainda não foi feita sob a ótica institucional (Palmer et al., 2016). 


\section{ORGANIZAÇÃO E PROCESSOS NOS TRIBUNAIS DE CONTAS}

Os tribunais de contas são organizações de auditoria governamental, responsáveis pela fiscalização financeira e entrega de serviços governamentais, que têm como principal função a emissão de um parecer prévio sobre as contas do Poder Executivo (Hidalgo, Canello, \& Lima-de-Oliveira, 2016; Speck, 2011). No Brasil existe(m) o Tribunal de Contas da União (TCU), com competências atreladas ao governo central, e os tribunais de contas regionais (TCs), que fiscalizam estados e municípios. Os TCs são autônomos e, apesar de seguirem um modelo napoleônico (Stapenhurst \& Titsworth, 2001), apresentam grande diversidade em relação à organização interna, à interpretação de normativas legais e aos processos de auditoria (Azevedo \& Lino, 2019; Lino \& Aquino, 2018; Nunes, Marcelino, \& Silva, 2019). A literatura pertinente traz evidências de más práticas organizacionais nos TCs (Loureiro et al., 2009; Teixeira, 2017). Os TCs são constituídos por membros do corpo instrutivo (auditores), deliberativo (conselheiros titulares), especial (conselheiros substitutos) e do Ministério Público de Contas (MPC) (Willeman, 2016). Enquanto os conselheiros titulares são, em sua maioria, indicados politicamente pelo Poder Executivo e pelo Poder Legislativo (Loureiro et al., 2009; Paiva \& Sakai, 2014), os outros atores ingressam na organização por meio de concursos públicos.

Em relação à hierarquia formal, os conselheiros titulares - e, principalmente, o presidente da casa têm plena discricionariedade sobre os rumos da organização e exercem influência sobre os demais atores organizacionais (Moreira \& Vieira, 2003). Faz parte do rol de ações a serem executadas pelos conselheiros a decisão sobre regras e normas de conduta internas dos TCs, conferindo a eles acesso às estratégias de poder que afetam de modo sistêmico as práticas internas (Lawrence, 2008). Ao mesmo tempo, a decisão sobre a distribuição de recursos também está a cargo dos conselheiros, especialmente no que se refere à indicação de cargos de confiança e funções gratificadas (Moreira \& Vieira, 2003).

Pesquisas anteriores sugerem que ao menos duas lógicas institucionais permeiam os tribunais de contas. A lógica técnico-profissional busca "proteger o interesse público e otimizar o gasto de recursos pelos governos de forma objetiva e impessoal” (Lino, 2019, p. 35). Outra lógica, denominada elitepatrimonialista, "busca a maximização (ou manutenção) de ganhos políticos, econômicos ou culturais através de barganhas interpessoais" (Lino, 2019, p. 35). Segundo as evidências de Loureiro et al. (2009) e Paiva e Sakai (2014), infere-se que a maior parte dos conselheiros de tribunais de contas seria guiada pela lógica elite-patrimonialista - por conta de seus laços político-partidários. O fenômeno de lógicas institucionais distribuídas de modo diferente ao longo da cadeia hierárquica de uma organização também ocorreu em Spence e Carter (2014). Dessa forma, o topo da hierarquia organizacional seguiria uma lógica de autointeresse mais próxima das más práticas - imorais, segundo Ashforth e Anand (2003) - o que é um dos fatores que geralmente inicia a disseminação de organizational wrongdoing ao longo da organização.

As evidências de práticas inadequadas nos TCs também envolvem reversão não justificada dos resultados de auditora. Azambuja, Teixeira, \& Nossa (2018) discutem o processo de prestação de contas anuais de governos municipais que são auditadas pelos TCs. Geralmente, ele se inicia no corpo instrutivo, onde auditores concursados planejam e executam a auditoria. Essa primeira auditoria gera um relatório técnico, que é encaminhado a um relator (em conjunto com um segundo relatório técnico, elaborado pelo MPC). O relator é selecionado entre os conselheiros titulares e emite uma opinião em acordo ou desacordo ao relatório técnico enviado pelo corpo instrutivo. Nesse momento, o relator pode solicitar mais informações a serem auditadas pelo corpo instrutivo, devido à possibilidade dos 
auditados se defenderem enviando mais dados anexados ao processo. Após a inspeção de todos os arquivos encaminhados pela defesa do auditado, o relator emite sua opinião e encaminha os autos ao tribunal pleno, que é o conselho formado por todos os conselheiros titulares para a votação e o julgamento final das contas. Membros do corpo especial (conselheiros substitutos) só participam desse processo no caso de necessidade de formação de um quórum mínimo. Mesmo quando irregularidades gravíssimas são apontadas pelo corpo instrutivo, relatores com raízes político-partidárias tendem a sugerir a aprovação das contas municipais de seus correligionários (Azambuja et al., 2018; Hidalgo et al., 2016). Tal reversão de relatórios pode ser potencializada devido à limitação da participação social no que se refere aos tribunais de contas (Rocha, 2017).

\section{MÉTODO}

Este artigo se baseia em um estudo de caso aprofundado, ou estudo de caso crítico (Yin, 2009), realizado no Tribunal de Contas do Estado do Rio de Janeiro (TCE-RJ), utilizando entrevistas (efetuadas entre 2017 e 2019), documentos e notícias de jornal. Os autores garantiram acesso ao caso após desdobramentos de investigações que apuraram um escândalo de corrupção no órgão, em março de 2017 - caracterizando um caso típico de organizational wrongdoing, dado que foi observado por agentes de controle, a saber, o MPF e a PF (Greve et al., 2010). Por meio de um método abdutivo (Reichertz, 2014), observou-se que parte das más práticas desenvolvidas no TCE-RJ se relacionava à lógica elite-patrimonialista, a despeito da existência de um grupo de atores guiados pela lógica técnico-profissional. Tais lógicas são apresentadas e descritas por Lino (2019) como incompatíveis dentro do processo de prestação de contas municipais. O caso foi selecionado de modo proposital (Lavrakas, 2008), por conta de suas características (presença de más práticas e de múltiplas lógicas institucionais) visando identificar as estratégias para manutenção de más práticas em uma organização com lógicas institucionais incompatíveis. Destaca-se que os resultados encontrados em casos únicos são generalizáveis para a teoria, mas não para as populações (Yin, 2009). Contudo, entrevistas complementares no campo reforçam que os resultados encontrados neste caso crítico podem ocorrer em outras organizações de auditoria do setor público no Brasil.

\subsection{Contexto do caso}

Entre dezembro de 2016 e março de 2017, as operações "Descontrole" e "O Quinto do Ouro" deflagradas pela PF e pelo MPF - investigaram um escândalo de corrupção no qual conselheiros do TCE-RJ recebiam, sob a forma de propina, participação em percentuais do custo de execução de contratos de obras e serviços, visando à aprovação da contratação de determinadas empresas (G1, 2017). Segundo a denúncia apresentada pela Procuradoria Geral da República (PGR, 2018), operacionalmente, o primeiro pagamento era feito na aprovação do edital pelo TCE-RJ, em seguida, ocorria outro pagamento na assinatura do contrato e, finalmente, outras parcelas eram pagas pelas empresas envolvidas quando recebiam os valores pela execução das obras. A denúncia cita uma operação criminosa conduzida por "membros do TCE-RJ, com a participação relevante de pessoas do Legislativo e do Executivo locais" (PGR, 2018, p. 18).

Segundo apurado, o conselheiro presidente do TCE-RJ controlava todo o fluxo de recursos ilícitos e todos os pagamentos ocorriam concomitantemente à execução das obras (PGR, 2018). 
As reuniões relacionadas ao caso e à entrega de envelopes de dinheiro vivo ocorreriam dentro do gabinete do presidente do TCE-RJ à época - em informações que ele mesmo cita em sua delação premiada (PGR, 2018).

Segundo a delação premiada de representantes das empresas citadas - Andrade Gutierrez, Carioca Engenharia e Odebrecht -, além dos conselheiros beneficiados, atores em diversos postos da organização participavam como intermediários ou operadores do escândalo que inicialmente prendeu, e subsequentemente afastou, todos (exceto um) (d)os conselheiros do TCE-RJ (PGR, 2018). Ainda segundo as investigações, um servidor do TCE-RJ recebia os pagamentos diretamente das empresas e, em seguida, repassava os valores ao conselheiro presidente - ou, em casos especiais, diretamente nos domicílios de outros conselheiros envolvidos. Os servidores citados como intermediários variavam conforme o gabinete e o presidente do tribunal. Cada gabinete de conselheiro envolvido tinha um servidor de confiança para auxiliar nos recebimentos; sendo que todos os citados nas investigações eram membros comissionados dos gabinetes dos conselheiros do TCE-RJ (PGR, 2018). Apenas um gabinete não participava do esquema denunciado. Segundo o jornal O Dia (2017), cada gabinete de conselheiro no TCE-RJ tinha 20 funcionários, sendo que o chefe e dois assessores recebiam salários superiores a R\$30 mil, valor superior à média dos auditores do corpo instrutivo. A denúncia da PGR (2018) analisada tem por foco a atuação dos conselheiros e não inclui terceiros envolvidos - ou seja, servidores do TCE-RJ -, de modo que as informações sobre participação de outros membros da organização ficam prejudicadas.

Cabe ressaltar que uma matéria da revista Veja (2008) apresentou evidências de uma investigação em que uma empresa de consultoria supostamente pagou para que as contas de municípios que eram seus clientes fossem aprovadas. Segundo as evidências, foram beneficiados o presidente do TCE-RJ, quatro conselheiros e alguns assessores de gabinetes.

O histórico descrito indica que as más práticas no TCE-RJ não seriam recentes e, não menos importante, não estariam relacionadas apenas a contratos de grande vulto - segundo PGR (2018), ou seja, no caso em que todos os contratos acima de $\mathrm{R} \$ 5$ milhões tinham $1 \%$ do valor destinado aos conselheiros do TCE-RJ.

As evidências sugerem que parte das más práticas também ocorreria no processo de prestação de contas anuais de prefeitos de municípios fluminenses. Tal proteção político-partidária para prefeitos municipais, envolvendo ganhos pecuniários para membros do TCE-RJ, foi alvo de uma comissão parlamentar de inquérito (CPI) na Assembleia Legislativa do Estado do Rio de Janeiro (ALERJ), Resolução n. 761/2009, de autoria da deputada Cidinha Campos. Nas justificativas dessa CPI, a autora diz que a empresa de consultoria citada "trabalhava para várias prefeituras fluminenses interessadas em aprovar suas contas no Tribunal e, para isso, não precisava de advogados. Bastava comprar Conselheiros" (constante no processo da CPI), corroborando a matéria publicada na revista Veja (2008). Cabe destacar que os conselheiros foram absolvidos por falta de provas no julgamento do Superior Tribunal de Justiça (STJ), em 2016, sendo esse parecer contrário à sugestão do MPF, que solicitava a condenação deles por corrupção passiva.

Apesar do escândalo recente, que afastou os conselheiros titulares do TCE-RJ, que envolveu predominantemente ganhos ilícitos via editais de contratação de obras e serviços, o foco deste artigo recai sobre a proteção de aliados políticos no processo de prestação de contas anuais - uma forma de organizational wrongdoing que ocorre e também é, de fato, corroborada por evidências supracitadas. 


\subsection{Coleta de dados}

As fontes utilizadas para a coleta de dados foram, preponderantemente, entrevistas e documentos. Como esse caso crítico foi tratado de modo relevante pela mídia especializada, notícias de jornal constituíram uma importante fonte de análise.

O acesso ao caso não era algo trivial e garantido - devido ao contexto de corrupção que se estabeleceu na organização e, subsequentemente, tornou-se público. Para acessar o caso e estabelecer confiança com os entrevistados, a primeira e necessária etapa de contato com o caso foi desenhada para obter permissão formal da então presidente interina do TCE-RJ. A permissão foi concedida após avaliação pela presidente interina de ofício enviado pelos autores, via e-mail, em 5 de dezembro de 2017. Em resumo, o ofício solicitava inicialmente entrevistas com a presidente interina, com o secretário-geral de controle externo e com o diretor-geral da Escola de Contas e Gestão (ECG) do TCE-RJ. A primeira entrevista ocorreu com a própria presidente interina, e obteve-se autorização para novas rodadas de entrevistas com ela e com os diversos atores organizacionais supracitados por meio de amostragem em bola de neve (Rapley, 2014). Apesar do provável viés dessa forma de amostragem, é a mais recomendada para estudos desta natureza (Javor \& Jancsics, 2016). Com esse apoio formal, os autores entrevistaram auditores, conselheiros, conselheiros substitutos e ex-membros do Ministério Público de Contas (MPC).

No total foram entrevistados 7 auditores e 3 conselheiros ou conselheiros substitutos e 1 exmembro do MPC. Os entrevistados potenciais foram contatados por e-mail, ou por contato telefônico por sugestão de um respondente anterior (amostragem em bola de neve). Alguns dos entrevistados participaram mais de uma vez, totalizando 16 entrevistas, com duração média de 54 minutos. As entrevistas foram realizadas a distância (telefone, Skype ou Whatsapp) atendendo a preferência e horário indicados pelo entrevistado. Alguns entrevistados preferiram fazer a entrevista fora do horário de trabalho, enquanto outros diretamente de sua mesa no TCE-RJ.

As entrevistas foram gravadas e transcritas de modo literal, sempre tempestivamente, para manter o ritmo da coleta e aumentar a qualidade das probing questions em entrevistas posteriores (Biernacki \& Waldorf, 1981; Kowal \& O’Connell, 2014) - o que pode incrementar a velocidade de saturação dos dados (Schreier, 2014). A transcrição literal buscou garantir a fidedignidade daquilo que foi dito (Christians, 2000).

Dado tema sensível tratado, os riscos éticos e preservação do respondente foi uma preocupação central dos autores. Considerando a inviabilidade da assinatura física de termo de consentimento livre e esclarecido, diversos procedimentos sugeridos para redução de riscos éticos, segundo Christians (2000), foram adotados. Primeiro, foi garantida e reiterada a participação voluntária aos participantes (Christians, 2000), os quais só entraram em detalhes de temas que se sentiram à vontade para comunicar. Segundo, todos os arquivos foram salvos em formato criptografado e sem conter informações que pudessem identificar o entrevistado. Terceiro, os achados da pesquisa foram enviados para checagem do respondente (Cho \& Trent, 2006) - member checking. Em geral entrevistados não sugeriram alterações substanciais na narrativa oferecida pelos autores; porém uma das sugestões relevantes foi o pedido de exclusão de uma tabela com informações sobre os antecedentes relacionados à experiência e à escolaridade de cada entrevistado, justificado pela garantia de seu anonimato, a qual foi aceita pelos autores. Quatro, foram utilizadas no artigo frases pronunciadas pelos entrevistados, porém, foi garantido que permaneceriam anônimos (atribuindo-se aleatoriamente para cada respondente um 
rótulo de $\mathrm{A}$ até $\mathrm{K}$ ) como forma de preservar os próprios indivíduos de retaliações internas e deixá-los confortáveis em abordar o tema.

Foram empregados dois roteiros semiestruturados para captar as práticas relevantes para manutenção de más práticas organizacionais no caso analisado. As mesmas práticas foram comparadas com as lógicas institucionais vigentes nos TCs detalhadas na literatura pertinente. Os roteiros foram aplicados com amplo uso de probing questions para tratar de temas emergentes (Eisenhardt, 1989).

O primeiro roteiro usou a técnica de entrevistas de elite (Leech, 2002; Richards, 1996) para não auditores focando as interações entre os conselheiros e o processo específico de prestação de contas anuais de governos. Tais interações foram separadas entre o momento atual e anteriormente ao escândalo de corrupção deflagrado, para observar como as práticas dos conselheiros poderiam impactar o trabalho de auditoria. Adicionalmente, perguntou-se sobre o fluxo de processos da prestação de contas anuais dos municípios, e sobre antecedentes sociais e organizacionais (trianguladas com documentos públicos).

O segundo roteiro, aplicado nas entrevistas com auditores, tratou das principais oportunidades e desafios para desempenhar seu papel na organização, suas atividades e sua rotina de trabalho diária (práticas), além de informações sobre antecedentes sociais e organizacionais (incluindo desde a formação até a experiência na organização e subunidade à qual estavam atrelados no organograma). Por fim, foi pedido que detalhassem as principais mudanças no TCE-RJ após o escândalo de corrupção e o afastamento dos conselheiros titulares.

De modo suplementar, analisaram-se notícias de jornal para triangular as práticas levantadas durante as entrevistas com o que foi revelado pela mídia (Flick, 2007). Foi selecionado o período de 1970 até 2018 para esta análise, pois: a) o contexto do caso mostra que más práticas organizacionais perduraram por anos; b) os conselheiros afastados iniciaram suas carreiras profissionais no final dos anos 1960; e, finalmente, c) há evidências de uma lógica elite-patrimonialista - associada às más práticas organizacionais - existente nos tribunais de contas desde antes da Constituição da República Federativa do Brasil (CF, 1988). Mais de 100 jornais publicados no Estado do Rio de Janeiro no período analisado foram utilizados, por meio da hemeroteca da Biblioteca Nacional. As seguintes palavras-chave foram usadas: "Tribunal de Contas", "Tribunal de Contas do Estado do Rio de Janeiro" e "TCE-RJ". No material levantado foram pesquisados os nomes dos conselheiros afastados devido ao escândalo de corrupção em 2017, bem como os nomes dos conselheiros que os substituíram. A amostragem de notícias analisadas seguiu a sugestão aleatória proposta em Bauer (2007). Também foram analisados documentos internos do TCE-RJ, como o regimento interno, o organograma, a lei orgânica, as minutas de reuniões e alguns processos de prestação de contas anuais selecionados aleatoriamente ou sugeridos pelos entrevistados e, por fim, manuais de auditoria.

O conjunto de dados e evidências reunido faz parte de um projeto mais amplo de pesquisa mantido pelos autores. Cada artigo que se utiliza desses dados tem seus próprios objetivos de pesquisa, como, por exemplo, analisar as formas de trabalho institucional utilizadas pelos atores no TCE-RJ para recompor o equilíbrio de poder no tribunal, considerando o escândalo um choque exógeno. Em outro artigo, os autores utilizam evidências do caso para analisar como a interferência político-partidária na dinâmica interna dos tribunais ameaça sua legitimidade fortalecendo redes de corrupção no âmbito dessas organizações de auditoria. 


\subsection{Procedimento de análise dos dados}

Foi feita a análise de conteúdo para reduzir e convergir padrões no material coletado (Schreier, 2014). Adotamos uma perspectiva neopositivista de análise das entrevistas (Roulston, 2014) em que a percepção dos entrevistados é tida como factual. Portanto, emprega-se múltiplas fontes de dados (i. e., os vários entrevistados) para validar os pontos de vista reportados, até o ponto em que novas informações não sejam adicionadas por novos informantes - ou seja, atingiu-se a saturação dos dados (Schreier, 2014).

Durante as entrevistas, os temas que emergiram foram discutidos em reuniões entre os autores, gerando o que se denomina preliminar open coding (Cornish, Gillespie, \& Zittoun, 2014). Os principais temas foram organizados em planilha eletrônica (Miles \& Huberman, 1994). Além de comparar os temas entre as entrevistas, eles também foram comparados com a literatura pertinente. Devido ao objetivo da pesquisa, o foco do processo de codificação recaiu sobre os "seis Cs" - causas, contextos, contingências, consequências, covariâncias e condicionantes (Thornberg \& Charmaz, 2014). Essa contínua interação entre a literatura pertinente e dados obtidos no caso, típica de estudos abdutivos, possibilitou o refinamento das categorias de análise que emergiram (Eisenhardt \& Graebner, 2007).

\section{MÁS PRÁTICAS ORGANIZACIONAIS NO TRIBUNAL DE CONTAS DO ESTADO DO RIO DE JANEIRO: RESULTADOS E DISCUSSÕES}

A análise da prestação de contas anual de prefeitos e governadores (além do presidente, no caso do TCU) é vista como uma das principais atividades dos tribunais de contas (Hidalgo et al., 2016). Tal análise gera o chamado parecer prévio, um relatório baseado no atendimento da gestão municipal às legislações vigentes de finanças públicas e contabilidade. Contudo, corroborando pesquisas anteriores, esta seção evidencia que, por vezes, esse processo de análise e julgamento nos TCs passa a se situar à margem das leis e baseia-se em comportamentos autointeressados (Azambuja et al., 2018; Loureiro, Teixeira, \& Prado, 2008; Teixeira, 2017), podendo prejudicar a sociedade - ao não mais proteger a gestão dos recursos públicos.

Na leitura do material de campo, identificamos diversas más práticas organizacionais. Algumas delas são utilizadas para operacionalizar o que identificamos como má prática embrionária. A má prática embrionária, na definição adotada, é a violação de origem praticada pelos atores envolvidos para cumprir seu principal objetivo. No caso em questão, a má prática embrionária é a negociação de resultados de julgamento pelos conselheiros com aliados políticos ou outros agentes atuando em nome dos auditados, com o objetivo de auferir ganhos pessoais. Para operacionalizar tal objetivo os envolvidos empregam uma série de práticas ilegítimas, que denominamos más práticas de suporte, revistas ou ampliadas ao longo do tempo, dependendo dos desdobramentos do contexto de ação. No caso do TCE-RJ, identificou-se um conjunto de más práticas de suporte (Quadro 1).

Segundo as entrevistas, más práticas organizacionais relacionadas ao processo de prestação de contas anual dos prefeitos no tribunal de contas podem ocorrer ao menos de duas formas distintas. Uma forma, explícita, é o uso de poder episódico - como descrito na seção de teoria. Por exemplo, quando conselheiros divergem e revertem pareceres técnicos de auditoria que recomendam a rejeição das contas de um aliado político. Essa prática vem sendo discutida na literatura atual, como em Azambuja et al. (2018) e Hidalgo et al. (2016). Outra forma, muito pouco explorada na literatura, é 
o uso de poder sistêmico baseado no controle de recursos e regras que guiam a conduta do corpo instrutivo de auditores, o que poderia mitigar a qualidade da auditoria, pois diminui a probabilidade de erros e irregularidades serem detectados em campo. Além disso, podem ocorrer ganhos na interação entre regras de poder sistêmico que reforçam o poder episódico dos conselheiros.

\section{QUADRO 1 MÁS PRÁTICAS DE SUPORTE E FORMAS DE PODER}

\begin{tabular}{|c|c|c|}
\hline Má prática & Poder episódico & Poder sistêmico \\
\hline Reversão de pareceres & $\begin{array}{l}\text { Conselheiros divergem do parecer técnico } \\
\text { sem justificativa. }\end{array}$ & - \\
\hline Diminuição da transparência & $\begin{array}{c}\text { Conselheiros impedem acesso aos } \\
\text { relatórios de auditoria. }\end{array}$ & - \\
\hline $\begin{array}{l}\text { Não votar pareceres } \\
\text { desfavoráveis }\end{array}$ & $\begin{array}{l}\text { Conselheiros e diretores fazem } \\
\text { composição seletiva da pauta e } \\
\text { "engavetam" processos. }\end{array}$ & - \\
\hline $\begin{array}{l}\text { Normas de reciprocidade } \\
\text { (compra de favores) }\end{array}$ & $\begin{array}{l}\text { Conselheiros fazem a provisão indevida } \\
\text { de cargos e funções. }\end{array}$ & - \\
\hline $\begin{array}{l}\text { Diminuição do tempo de } \\
\text { auditoria in loco }\end{array}$ & Conselheiros editam as regras. & $\begin{array}{c}\text { Regras de alocação de tarefas que levam a } \\
\text { consumo de horas de auditoria em tarefas } \\
\text { não essenciais. }\end{array}$ \\
\hline $\begin{array}{l}\text { Interferência no planejamento de } \\
\text { auditoria }\end{array}$ & $\begin{array}{c}\text { Conselheiros e diretores fazem exercício } \\
\text { da influência sobre como, o quê e quando } \\
\text { auditar. }\end{array}$ & $\begin{array}{c}\text { (i) uso de normas de reciprocidade; } \\
\text { (ii) alocação de tarefas restringe espaço de } \\
\text { planejamento. }\end{array}$ \\
\hline $\begin{array}{l}\text { Silenciamento das demandas de } \\
\text { auditores }\end{array}$ & Conselheiros decidem o organograma. & $\begin{array}{l}\text { A hierarquização mantém o conselho } \\
\text { inacessível às demandas dos auditores. }\end{array}$ \\
\hline
\end{tabular}

Fonte: Elaborado pelos autores.

Uma das causas da alta taxa de divergência e reversão sobre os pareceres técnicos - uma característica de poder episódico utilizado pelos Conselheiros - é a falta de transparência nos processos-chave da organização, que não eram publicizados nem sob consulta. Até o momento em que o escândalo de corrupção veio à tona, os relatórios técnicos de auditoria não eram divulgados na íntegra em nenhum meio (físico ou eletrônico).

"Até antes do afastamento dos Conselheiros, os relatórios de auditoria não eram divulgados na integra. Era só um resumo do relatório. Também existiam sessões [reuniões] secretas de Conselheiros" (Respondente A).

Dessa forma, era impossível o exercício do controle social sobre as atividades de auditoria e, portanto, avaliar se havia divergência entre os relatórios de auditores e julgamentos dos conselheiros. 
Cabe destacar que tal divergência pode ocorrer, desde que justificada com base legal, contábil ou financeira, o que nem sempre era o caso. Segundo entrevista com o respondente A, os conselheiros votavam em desacordo do corpo técnico "de acordo com a sua consciência", sem fundamentação e justificativa.

Como consequência da falta de transparência, sob o contexto de conselheiros guiados por uma lógica institucional elite-patrimonialista, a Tabela 1 mostra que a média de divergência entre conselheiros e corpo técnico (até o escândalo de corrupção ser revelado; as contas de 2016 já foram julgadas pelo novo corpo de conselheiros) era considerável. Um exemplo de grande vulto:

"Houve um processo do Maracanã, esse sim teve uma divergência meio que inexplicável, mas porque o relator... ele se valeu da ausência de transparência do Tribunal à época, em que ele mudou o voto em relação ao entendimento que foi construído pelo corpo instrutivo" (Respondente E).

A estratégia de reversão é utilizada apenas como último recurso, devido ao custo político e de legitimidade, por ser facilmente verificável - desde que haja transparência dos relatórios de auditoria ou que, ao menos, a opinião do corpo instrutivo conste no parecer prévio emitido pelo corpo deliberativo, é possível para qualquer parte interessada comparar os relatórios e observar se houve divergência.

TABELA 1 DIVERGÊNCIA DAS DECISÕES DE AUDITORES, RELATORES E VOTO FINAL DO CORPO DELIBERATIVO

\begin{tabular}{lccccc} 
& $2011[\%]$ & $2012^{1}[\%]$ & $2013[\%]$ & $2014[\%]$ & $2015[\%]$ \\
\hline Aprovação de auditores & 65 & 40 & 75 & 60 & 72 \\
Aprovação final & $65[100]$ & $40[100]$ & $75[100]$ & $60[100]$ & $72[100]$ \\
Rejeição de auditores & 26 & 51 & 16 & 31 & 19 \\
Divergência do relator & $18[69]$ & $20[39]$ & $12[75]$ & $19[61]$ & $9[47]$ \\
Divergência do corpo deliberativo & $4[15]$ & $5[10]$ & $3[19]$ & $9[29]$ & $2[11]$ \\
Rejeição final & $4[15]$ & $26[51]$ & $\mathbf{1}[6]$ & $3[10]$ & $\mathbf{8}[42]$ \\
\hline
\end{tabular}

${ }^{1}$ Ano eleitoral, com regras específicas da Lei de Responsabilidade Fiscal (LRF) que impactam o número de rejeições. Fonte: Elaborada pelos autores.

Segundo o presidente do TCE-RJ, à época, havia alguma preocupação relativa a divergências não fundamentadas. Nas palavras dele, "o corpo deliberativo tinha preocupação em não violentar a análise técnica da equipe de instrução" (PGR, 2018, p. 85), de modo que exigências do corpo técnico eram postergadas por decisão dos conselheiros - mas nem sempre diretamente revertidas. Portanto, outra má prática existente no TCE-RJ era o engavetamento de processos e pedido de vista em processos, entre outras estratégias para postergar o julgamento para um momento favorável ao auditado. Isso estaria ligado à capacidade de influenciar o que será ou não objeto de discussão (Pfeffer, 1981). 
"[Outra coisa] que os Conselheiros podiam fazer, e tal, era segurar a tramitação do processo" (Respondente E).

"No Rio de Janeiro existiam 54 processos guardados, rigorosamente, escondidos na gaveta do Presidente que organizava o sistema de corrupção, por quê? Porque aqueles não poderiam vir à tona, não poderiam ser sequer julgados. Porque, mesmo com toda manobra que se pudesse fazer no plenário, na hora em que fossem julgados - e nesse caso os TCs disponibilizam as informações depois do julgamento - as pessoas veriam que haveria uma distância extraordinária entre o que foi anotado [pelo corpo instrutivo] e o que foi resultante do julgamento" (Respondente K).

Essa é outra forma de poder episódico, cujas ações podem ser tomadas por conselheiros ou por outros atores em cargo de chefia intermediária na organização. Por exemplo, segundo os entrevistados, até o escândalo de corrupção ser revelado, um parente do presidente do tribunal de contas trabalhava em um cargo específico no qual todos os processos abertos contra os municípios tramitavam sob sua alçada. Dessa forma, ele tinha acesso a informações restritas e, segundo entrevista com o respondente A, "passava a informação para o município, vendia a informação e cobrava por isso". Contudo, por vezes, não era possível atuar em defesa dos municípios - assim, o mesmo respondente diz que, se houvesse "alguma coisa que pudesse comprometer [os Prefeitos], ou que ele não tivesse como não atender, ele segurava o processo ao máximo".

O fato de o parente do presidente do tribunal atuar dessa maneira também expõe outra má prática organizacional: a provisão indevida de cargos em comissão. Tais comissionados passam a dever favores e operam segundo a norma da reciprocidade (Palmer, 2008). Parte desses favores é auxiliar na proteção de municípios, seja disponibilizando informação privilegiada, seja atuando diretamente nas peças técnicas do processo, criando justificativas para a não rejeição de contas do Poder Executivo. Além disso, segundo relato dos entrevistados, a proteção do município pelo conselheiro pode lhe garantir cargos em prefeituras municipais que seriam ocupados por pessoas ligadas aos conselheiros. Ainda, diversos respondentes (entre eles, A, E, K) citam que o alto número de funções gratificadas no TC reduz o incentivo para que aqueles que seriam naturalmente guiados por uma lógica técnicoprofissional se manifestem contrários ao status-quo.

Assim a lógica elite-patrimonialista está presente em diversos níveis organizacionais, e guia o comportamento também de atores concursados que recebem ganhos pecuniários por sua atuação em cargos em comissões e funções específicas. Essa difusão da lógica afasta a proposição de que apenas e unicamente os conselheiros seriam os operadores responsáveis pelas más práticas organizacionais no TC. Destaca-se que também é rejeitada a proposição de que a tecnocracia seria a solução para o problema em questão, haja visto que servidores concursados também operam más práticas. Conforme o respondente $\mathrm{H}$, outra forma de poder episódico utilizado à época para manter más práticas organizacionais é o uso de força, como ameaças de realocação do auditor em outra localidade ou ameaças de exoneração da função gratificada.

Como tratado por Dunn e Jones (2010), o balanceamento entre lógicas em uma organização oscila ao longo do tempo segundo o aumento ou a diminuição do poder de determinado grupo. Cabe recordar que no caso em questão, similar a Spence e Carter (2014), as estratégias utilizadas decorrem da lógica político-elitista ser preponderante no topo da hierarquia organizacional. Ainda, a centralidade das lógicas institucionais se altera conforme o fluxo de trabalho da auditoria. Os trabalhos de auditoria 
são iniciados em uma lógica puramente técnico-profissional porém são finalizados na etapa judicante em uma lógica elite-patrimonialista. Há, portanto, uma zona cinzenta durante o fluxo da auditoria, em que atores provavelmente mesclam as duas lógicas vigentes no TC.

No caso em questão, para manter o poder e as más práticas organizacionais, os conselheiros (especialmente o presidente) utilizam as funções gratificadas para gerar os incentivos necessários para auditores - na base da hierarquia - seguirem a norma da reciprocidade - sob a lógica elitepatrimonialista. Dessa forma, é possível que a lógica preferida se alastre em direção à base da organização e para a origem do fluxo de trabalho, normalizando e rotinizando as más práticas organizacionais - o que é denominado "cultura de corrupção" por um dos entrevistados.

"A gente sabe que existe uma cultura de corrupção que é difícil de romper. Os servidores [concursados] também acabam absorvendo isso, né? Na omissão, na conivência... Então, é uma coisa que infelizmente tem... essa cultura que precisa ser rompida" (Respondente A).

"Algumas vezes acontece que nossos chefes [diretores e coordenadores de auditoria, função gratificada] ficam sabendo que nosso relatório vai sugerir uma reprovação de contas. Imagina que você está no café e conta para alguém sobre o processo. Mais cedo ou mais tarde o chefe vai ficar sabendo e, se for do interesse dele, ele vai agir. Por exemplo, eu sei de casos em que o auditor deixou o processo em cima da mesa depois do expediente para continuar trabalhando pela manhã; mas o chefe pegou o processo e realocou para outro auditor [mais propenso a seguir uma lógica elite-patrimonialista e sugerir aprovação das contas] ou até mesmo emitiu uma sugestão de aprovação ele mesmo antes da manhã” (Respondente $\mathrm{H}$ ).

Além das práticas relacionadas ao uso de poder episódico, outra maneira de sustentar organizational wrongdoing é por meio de poder sistêmico. As rotinas comuns são condicionadas por regras que afetam o trabalho técnico de auditoria do corpo instrutivo - reduzindo a capacidade de reconhecimento de erros e irregularidades por parte dos auditores, como, por exemplo, sobrecarga de trabalho, centralização do planejamento de auditoria, peças não informatizadas e distanciamento entre o núcleo de poder e os departamentos subalternos. Segundo o respondente C, a sobrecarga em alguns pontos da organização era tanta que tornava o trabalho de auditoria "humanamente impossível”.

Para auditoria é relevante que os auditores tenham liberdade e independência no processo de seleção dos objetos de auditoria, usualmente conforme critérios de risco, materialidade, relevância e oportunidade. Contudo, no período analisado, havia sobrecarga de trabalho em funções acessórias de auditoria, que não eram vistas como essenciais pelos auditores, mas eram reforçadas por regras sistêmicas impostas pelos conselheiros. Em resumo, diversos respondentes (entre eles, C, D, E, H) reportaram que havia remessas obrigatórias em papel que chegavam ao tribunal, independentemente de serem requisitadas, e deveriam ser analisadas. Esse volume de informações gerava menor tempo para auditoria in loco e um acúmulo de processos a analisar.

"[A independência para selecionar objetos de auditoria] não era a cultura do Tribunal. Por causa dos envios obrigatórios, os atos eram enviados pelos jurisdicionados, os contratos, sempre que um contrato era celebrado, contrato, edital, eles eram enviados com uma relação de documentos 
pré-determinados para o Tribunal de Contas. Havia uma ordem, não escrita, mas difundida, de que tudo que desse entrada no Tribunal deveria ter alguma análise. Então, o número de processos que entra no Tribunal, e que entrava até então, era realmente muito grande - e não tinha como dar conta disso! A gente não conseguia realizar inspeção in loco, que é a maneira mais efetiva de você encontrar e se deparar com os problemas... porque você tinha que ficar perdendo tempo analisando papel, analisando folha de papel. [...] Você analisa aquilo que o jurisdicionado te mandou, nem foi você que determinou o envio" (Respondente E).

Segundo outro entrevistado:

"Na SGE [Secretaria-Geral de Controle Externo] a gente tinha aproximadamente 500 servidores, dos quais $82 \%$ ficavam fazendo análise de legalidade de processos de contrato e outros atos, internamente. Então os jurisdicionados enviavam para cá um contrato ou então algum ato como um convênio, consórcio, enfim... Eles enviavam todos os atos e contratos para cá e a gente analisava a legalidade desses atos e contratos segundo a documentação que eles tinham enviado. Então a gente recebia milhares, centenas de milhares de processos todo ano para fazer essa análise meramente formal, entendeu? E aí, a gente percebeu o seguinte... Foi feito um estudo, e a gente percebeu que muitas vezes quando analisávamos a formalidade dos contratos estava tudo OK, mas quando íamos in loco analisar o mesmo contrato a gente identificava diversas irregularidades. No caso de obras: a obra não tinha sido executada, os parâmetros definidos no contrato não tinham sido cumpridos, enfim, os critérios mínimos de qualidade não tinham sido observados. Então, na verdade, a gente dava conhecimento dos processos aqui e quando a gente ia fiscalizar in loco por meio de auditoria de conformidade a gente via que não era nada daquilo. $\mathrm{E}$ a gente empregava mais de $80 \%$ da nossa mão de obra para fazer esse trabalho que não tinha efetividade nenhuma para a sociedade" (Respondente G).

Dessa maneira, apesar dos auditores continuarem executando uma tarefa técnica (análise de remessas obrigatórias em papel), eles não conseguiam executar práticas vistas como mais efetivas, de modo que havia desperdício de recursos relacionados ao tempo de auditoria. E, por conta do distanciamento entre o núcleo decisor (conselheiros) e o corpo técnico de auditoria, a situação nunca se alterava. Quando perguntado se foram feitas tentativas de apresentar esses estudos supracitados para o corpo deliberativo, um respondente disse:

"Várias [tentativas]. Sim, sim... Inclusive de aumentar o limite [mínimo] de valor para a análise de contrato, para não mandar contrato para cá de qualquer valor e a gente ter que analisar. Porque era tudo! Se mandassem para cá um contrato de $\mathrm{R} \$ 800,00$ a gente ia ter que analisar. Aí, imagine o custo do controle, você ter que pagar um auditor para auditar um contrato de $\mathrm{R} \$ 800,00$. É um custo muito alto para a sociedade, e a gente não conseguia mudar. Nem isso a gente conseguia" (Respondente G).

Ao serem questionados se não era possível ao menos apresentar aos conselheiros as vantagens identificadas nos estudos de substituir a auditoria remota por auditoria in loco, a resposta esbarra novamente em mecanismos de poder episódico. 
"Não, até chegava [os estudos]. Mas não conseguia aprovar. A proposta não passava da Presidência. Parava ali na Presidência. Nem ia para o corpo deliberativo. A Presidência tem que pegar o normativo e pautar para votação. Se a Presidência não pauta, não é votado e não sai nada. É simplesmente não colocar em pauta para votação" (Respondente G).

Dessa forma, as normas que mantêm o distanciamento entre conselheiros e auditores diminuem a negociação e entendimento de atores com diferentes orientações e perspectivas na organização. Assim, a lógica preferida pelos atores com poder se reforça e a lógica institucional conflitante não tem espaço para emergir - devido às regras formais. Esse jogo, finalmente, conduz à manutenção das estruturas de poder e das práticas associadas a organizational wrongdoing.

A execução de auditoria de legalidade remota via papel, em partes, também se devia à subutilização de sistemas informatizados e automatizados para auxiliar os trabalhos técnicos. Por vezes, citou-se que os auditores eram obrigados a utilizar planilhas com dados defasados para direcionar a auditoria, pois não havia recebimento tempestivo dos dados. Também se relatou (respondente D) que as áreas de controle externo, responsável pela auditoria, e a diretoria de informática sofriam com problemas de coordenação; dessa forma, as demandas de controle externo não encontravam eco na produção de sistemas. Um dos entrevistados sugeriu que a diretoria de informática não produzia os resultados esperados por conta de sua composição, em termos de recursos humanos.

"A Diretoria-Geral de Informática, atualmente, no organograma do TC, não é vinculada à Secretaria-Geral de Controle Externo. Ela tem uma vinculação mais próxima à presidência do Tribunal. E ela [DGI], até bem pouco tempo - mas isso foram coisas que foram reveladas no calor de todas aquelas confusões envolvendo os Conselheiros - ela era utilizada como um lugar para depositar os indicados, os apadrinhados, enfim... Havia muita gente que ocupava um cargo na Diretoria de Informática e que não trabalhava com isso, que não trabalhava na área de informática [...] era até comum haver em uma semana uma determinada pessoa e na semana seguinte outra que ele nunca tinha visto na vida [trabalhando na DGI]. Enfim, era uma bagunça generalizada" (Respondente E).

Em resumo, as evidências sugerem que as relações de poder existentes na organização analisada foram fundamentais para a manutenção de más práticas ao longo dos anos. Além disso, observouse que a manutenção dessas más práticas dependia, em grande parte, do poder relativo associado aos atores guiados pela lógica institucional elite-patrimonialista (que se caracteriza por barganhas políticas visando ao benefício próprio).

Tais evidências permitem entender as causas de provável subversão da estrutura de poder hierárquico, que idealmente seria desenhada para aumentar a coordenação e facilitar as transações internas em uma organização. Ainda, reconhecer que as más práticas de suporte identificadas são soluções adotadas para suportar o objetivo final de uma má práticas embrionária.

O que esses achados sugerem é que as pesquisas devem analisar se organizational wrongdoing se mantém justamente pela lógica institucional dominante em cada segmento da organização. A lógica institucional que envolve e é mantida pelos atores com poder induz práticas que podem transgredir a lei ou mostram-se imorais. Nesses casos, é mais provável que organizational wrongdoing se torne 
parte do "DNA" da organização, ou seja, dissemine-se em diferentes departamentos e torne-se algo usado para diferentes finalidades. Para tal, os atores com maior poder devem engajar-se em diversas estratégias, que induzem más práticas de suporte, para manter a preponderância de sua lógica preferida. No caso analisado, é importante observar alguns aspectos relevantes:

1) A falta de transparência nas práticas adotadas pelos atores com poder impede o acesso de outras fontes de legitimidade às rotinas organizacionais, ao mesmo tempo que diminui a informação sobre as práticas no ambiente intraorganizacional. Dessa forma atores (subalternos ou não) guiados por uma lógica institucional incompatível não conseguem acessar recursos informacionais para combater as práticas vigentes; 2 )

2) Atores com poder desenham regras formais que permitem a criação de relações intraorganizacionais que suscitam a norma de reciprocidade (Palmer, 2008) dos atores subalternos. A reciprocidade desses atores-chave (subalternos) é importante para sustentar a lógica institucional preferida pelos atores com poder em diferentes departamentos da organização - institucionalizando as más práticas.

3) Além disso, os atores com poder podem atuar visando a diminuir a centralidade das lógicas incompatíveis (guiadas por ações morais e legais) na organização. Ao diminuir a preponderância de tais lógicas, há "espaço livre" para a manutenção e a expansão das práticas de organizational wrongdoing.

4) Observa-se que existem "níveis" de más práticas organizacionais, em que diversas más práticas de suporte são desenhadas e aplicadas por atores interessados em atingir os objetivos relacionados a uma má prática embrionária.

\section{CONCLUSÕES}

A análise mostra, no caso do TCE-RJ, que as más práticas organizacionais se perpetuam por meio de estratégias adotadas por atores com maior poder, favorecidas pela lógica institucional elitepatrimonialista (Lino, 2019). No caso em questão, um grupo de agentes parte da rede de influência dos conselheiros, como assessores e diretor de auditoria, para perpetuar más práticas (organizational wrongdoing) induzidas e suportadas pelo desbalanceamento de poder na acomodação interna de lógicas institucionais divergentes ou incompatíveis.

Tais práticas no caso em estudo surgem e ocorrem em processos organizacionais, imbricados em rotinas e estruturas de cargos e relações de poder distribuídas em toda organização. As práticas foram continuamente replicadas com apoio de outros atores, baseadas na norma da reciprocidade. Dentro da lógica elite-patrimonialista, as estratégias incluíram o uso de baixa transparência de relatórios e decisões, regras de reciprocidade (troca de favores) e, finalmente, a diminuição da centralidade de lógicas institucionais incompatíveis (não alinhadas) com as más práticas. Os conselheiros atuavam legitimando e construindo as normas sistêmicas, já os assessores e diretores em função gratificada que deviam reciprocidade protegiam ativamente a manutenção das más práticas.

Os resultados contribuem de três formas:

1) Agregam à literatura sobre wrongdoing a influência de lógicas institucionais predominantes, dado o efeito da lógica dominante operando na atuação de conselheiros;

2) Indicam que o desbalanceamento entre lógicas pode contribuir às más práticas, se atores com poder apoiarem a lógica favorável às más práticas; 
3) Por fim, oferecemos para literatura sobre organizações de auditoria em países latino-americanos uma explicação teórica para a influência política no desempenho organizacional.

Sobre o último ponto mencionado, o foco da literatura sobre auditoria, nacional e internacional, tem analisado de forma isolada as más práticas e o desenho organizacional. Este artigo consolida os estudos anteriores e aponta que tais práticas são diversas em sua natureza, mas similares em seu objetivo. A má prática embrionária, que no caso seria a negociação de resultados de votações, acaba desdobrando-se em um conjunto de más práticas de suporte, todas elas apoiadas pela lógica elitepatrimonialista. Com isso, este estudo dá uma resposta mais ampla acerca de tais efeitos e destaca que um dos únicos mecanismos de reequilíbrio entre lógicas conflitantes, as quais são parte sine qua non dada a estrutura organizacional dos tribunais de contas no cenário atual, seria ter duas lógicas com poder balanceado - de forma que houvesse uma relação de accountability e checks and balances entre elas. Assim, as práticas ilegítimas poderiam ser cerceadas dentro do próprio ambiente organizacional. Atualmente, a preponderância da lógica elite-patrimonialista e o enfraquecimento da lógica técnico-profissional (fruto do trabalho dos conselheiros e de sua rede relacional) reduzem as chances de reverter o cenário de más práticas organizacionais. Com isso, o tribunal de contas deixa de cumprir sua função social e passa cada vez mais a ser questionado socialmente.

Em termos de agenda futura de pesquisa, os autores sugerem que sejam analisados outros casos de tribunais de contas, observando se as estratégias de suporte listadas são empregadas, e que se deduza se existiria o potencial uso da má prática embrionária ou, se não, o que estaria inibindo o sucesso total da estratégia de captura pela lógica elite-patrimonialista. Ademais, sugere-se a análise do que inibe que atores ligados à lógica técnica se agreguem em torno da categoria de auditores externos, em um movimento nacional, e assumam uma posição de resistência à lógica institucional dominante. 


\section{REFERÊNCIAS}

Arantes, V. A., Gusmão, I. B., \& Costa, M. C. (2019). Análise do relatório de guidance em empresas investigadas pela Polícia Federal: exame sob a perspectiva do gerenciamento de impressões. Revista de Contabilidade e Organizações, 13, e148176.

Ashforth, B. E., \& Anand, V. (2003). The normalization of corruption in organizations. Research in Organizational Behavior, 25, 1-52.

Ashforth, B. E., \& Lange, D. (2016). Beware of organizational saints: how a moral self-concept may foster immoral behavior. In D. Palmer, K. SmithCrowe, \& R. Greenwood (Eds.), Organizational wrongdoing: key perspectives and new directions (pp. 305-336). Cambridge, England: Cambridge University Press.

Azambuja, P. A., Teixeira, A., \& Nossa, S. N. (2018). Aprovação de contas municipais com irregularidades gravíssimas: quando a auditoria técnica não é suficiente. Revista de Contabilidade e Organizações, 12, e149212.

Azevedo, R. R., \& Lino, A. F. (2018). O distanciamento entre as normas de auditoria e as práticas nos tribunais de contas. Sociedade, Contabilidade e Gestão, 13(2), 9-27.

Battilana, J. (2006). Agency and institutions: the enabling role of individuals' social position. Organization, 13(5), 653-676.

Bauer, M. W. (2007). Classical Content Analysis: a review. In Eds. (Bauer, M. W.; Gaskell, G.) Qualitative Researching with text, image and sound (pp. 131-151). SAGE, London.

Besharov, M. L., \& Smith, W. K. (2014). Multiple institutional logics in organizations: explaining their varied nature and implications. Academy of Management Review, 39(3), 364-381.

Biernacki, P., \& Waldorf, D. (1981). Snowball sampling: problems and techniques of chain referral sampling. Sociological Methods \& Research, 10(2), 141-163.

Birkholz, C. (2015). Hybrid organizing under institutional complexity: insights from impact investing and social entrepreneurship (Ph.D. Thesis). University of St. Gallen, St. Gallen, Switzerland.
CBS. (2019, 31 Outubro). Uber allegedly paid $\$ 100,000$ ransom and had hackers sign NDAs after massive data breach. Recuperado de https://www. cbsnews.com/news/uber-hack-company-allegedlypaid-hackers-ransom-had-them-sign-ndas/

Cho, J., \& Trent, A. (2006). Validity in qualitative research revisited. Qualitative Research, 6(3), 319-340.

Christians, C. G. (2000). Ethics and politics in qualitative research. In N. K. Denzin, \& Y. S. Lincoln (Eds.), Handbook of qualitative research (2nd ed., pp. 133-155). Thousand Oaks, CA: SAGE.

Constituição da República Federativa do Brasil, de 5 de outubro de 1988. (1988). Brasília, DF.

Cornish, F., Gillespie, A., \& Zittoun, T. (2014). Collaborative analysis of qualitative data. In U. Flick (Ed.), The SAGE handbook of qualitative data analysis (pp. 79-93). Thousand Oaks, CA: SAGE.

Deephouse, D. L., \& Suchman, M. (2008). Legitimacy in organizational institutionalism. In R. Greenwood, C. Oliver, K. Sahlin, \& R. Suddaby. (Eds.), The SAGE handbook of organizational institutionalism (pp. 4977). Thousand Oaks, CA: SAGE.

Dunn, M. B., \& Jones, C. (2010). Institutional logics and institutional pluralism: the contestation of care and science logics in medical education, 1967-2005. Administrative Science Quarterly, 55, 114-149.

Eisenhardt, K. M. (1989). Building theories from case study research. The Academy of Management Review, 14(4), 532-550.

Eisenhardt, K. M., \& Graebner, M. E. (2007). Theory building from cases: opportunities and challenges. Academy of Management Journal, 50(1), 25-32.

Flick, U. (2007). The SAGE qualitative research kit. Designing qualitative research. Thousand Oaks, CA: SAGE.

G1. (2017, 29 de março). Operação Quinto do Ouro nasceu de delações. Recuperado de https://g1.globo. $\mathrm{com} / \mathrm{rio}$-de-janeiro/noticia/operacao-quintodo-ouro-nasceu-de-delacao-de-ex-diretor-daodebrecht.ghtml

Greve, H. R., Palmer, D., \& Pozner, J. E. (2010). Organizations gone wild: the causes, processes, and consequences of organizational wrongdoing. Academy of Management Annals, 4(1), 53-108. 
Hardy, C., \& Clegg, S. (2006). Some dare call it power. In S. R. Clegg, C. Hardy, T. B. Lawrence, \& W. R. Nord (Eds.), The SAGE handbook of organization studies (pp. 754-776). Thousand Oaks, CA: SAGE.

Hidalgo, F. D., Canello, J., \& Lima-de-Oliveira, R. (2016). Can politicians police themselves? Natural experimental evidence from Brazil's audit courts. Comparative Political Studies, 49(13), 1739-1773.

Intercept Brasil. (2019, 9 de junho). As mensagens secretas da Lava-Jato. Recuperado de https:// theintercept.com/series/mensagens-lava-jato/

Jarzabkowski, P., Balogun, J., \& Seidl, D. (2007). Strategizing: the challenges of a practice perspective. Human Relations, 60(1), 5-27.

Jávor, I., \& Jancsics, D. (2016). The role of power in organizational corruption: an empirical study. Administration \& Society, 48(5), pp. 527-558.

Kellogg, K. C. (2011). Hot lights and cold steel: cultural and political toolkits for practice change in surgery. Organization Science, 22, 482-502.

Khan, R. S. (2012). The sociology of elites. Annual Review of Sociology, 38, 361-377.

Kowal, S., \& O'Connell, D. C. (2014). Transcription as a crucial step of data analysis. In U. Flick (Ed.), The SAGE handbook of qualitative data analysis (pp. 64-79). Thousand Oaks, CA: SAGE.

Lavrakas, P. J. (2008). Encyclopedia of survey research methods. Thousand Oaks, CA: SAGE.

Lawrence, T. B. (2008). Power, institutions and organizations. In R. Greenwood, C. Oliver, K. Sahlin, \& R. Suddaby. (Eds.), The SAGE handbook of organizational institutionalism (pp. 170-198). Thousand Oaks, CA: SAGE.

Lawrence, T. B., \& Suddaby, R. (2006). Institutions and institutional work. In S. R. Clegg, C. Hardy, T. B. Lawrence, \& W. R. Nord (Eds.), Handbook of organization studies (2nd ed., pp. 215-254). Thousand Oaks, CA: SAGE.

Lawrence, T. B., Winn, M. I., \& Jennings, P D. (2001). The temporal dynamics of institutionalization. Academy of Management Review, 26(4), 624-644.

Leech, B. L. (2002). Asking questions: techniques for semi-structured interviews. Political Science and Politics, 35(4), 665-668.
Lino, A. F. (2019). As lógicas conflitantes no tribunal de contas e o enfraquecimento de sua relevância social (Tese de Doutorado). Universidade de São Paulo, Ribeirão Preto, SP.

Lino, A. F., \& Aquino, A. C. B. (2018). The diversity of the Brazilian regional audit courts on government auditing. Revista Contabilidade \& Finanças, 29(76), 26-40.

Lounsbury, M. (2008). Institutional rationality and practice variation: new directions in the institutional analysis of practice. Accounting, Organizations and Society, 33(4-5), 349-361.

Loureiro, M. R., Teixeira, M. A. C., \& Prado, O. (2008). Construção de instituições democráticas no Brasil contemporâneo: transparência das contas públicas. Organizações \&Sociedade, 15(47), 107-119.

Loureiro, M. R., Teixeira, M. A. C., \& Moraes, T. C. (2009). Democratização e reforma do Estado: o desenvolvimento institucional dos tribunais de contas no Brasil recente. Revista de Administração Pública, 43(4), 739-772.

Lowndes, V., \& Roberts, M. (2013). Why institutions matter: the new institutionalism in political science. Basingstoke, England: Palgrave Macmillan.

Miles, M. B., \& Huberman, A. M. (1994) Qualitative data analysis: an expanded sourcebook (2nd ed). London, England: SAGE.

Moreira, E. D. A., \& Vieira, M. M. F. (2003). Estruturas de poder e instituições como determinantes da efetividade do Tribunal de Contas do Estado de Pernambuco. Organizações \& Sociedade, 10(26), 119-138.

Nunes, S. P. P., Marcelino, G. F., \& Silva, C. A. T. (2019). Os tribunais de contas na interpretação da Lei de Responsabilidade Fiscal. Revista de Contabilidade e Organizações, 13, e145151.

O Dia. (2017, 4 de abril). Equipes de cada conselheiro do TCE custam até $R \$ 430$ mil por mês. Recuperado de https://odia.ig.com.br/_conteudo/rio-dejaneiro/2017-04-04/informe-equipes-de-cadaconselheiro-do-tce-custam-ate-r-430-mil-por-mes. html

Paiva, N., \& Sakai, J. (2014). Quem são os conselheiros dos tribunais de contas. São Paulo, SP: Transparência Brasil. 
Palmer, D. (2008). Extending the process model of collective organizational wrongdoing. Research in Organizational Behavior, 28, 107-135.

Palmer, D. (2013). Normal organizational wrongdoing: a critical analysis of theories of wrongdoing in and by organizations. Oxford, England: Oxford University Press.

Palmer, D. (2017). Institutions, institutional theory, and organizational wrongdoing. In R. Greenwood, C. Oliver, T. B. Lawrence, \& R. E. Meyer (Eds.), The SAGE handbook of organizational institutionalism (pp. 737-758). Thousand Oaks, CA: SAGE.

Palmer, D., Smith-Croweand, K., \& Greenwood, R. (2016). Organizational wrongdoing: key perspectives and new directions (pp. 203-234). Cambridge, England: Cambridge University Press.

Pfeffer, J. (1981). Power in organisations. Boston, MA: Pitman.

Phillips, N., Lawrence, T. B., \& Hardy, C. (2004). Discourse and institutions. Academy of Management Review, 29(4), 636-652.

Procuradoria Geral da República. (2018). Denúncia: Inquérito 1201/DF - Operação Quinto do Ouro. Brasília, DF: Autor.

Rapley, T. (2014). Sampling strategies in qualitative research. In U. Flick (Ed.), The SAGE handbook of qualitative data analysis (pp. 49-63). Thousand Oaks, CA: SAGE.

Reichertz, J. (2014). Induction, deduction, abduction. In U. Flick (Ed.), The SAGE handbook of qualitative data analysis (pp. 123-135). Thousand Oaks, CA: SAGE.

Richards, D. (1996). Elite interviewing: approaches and pitfalls. Politics, 16(3), 199-204.

Rocha, D. G. (2017). As duas faces de Jano dos tribunais de contas brasileiros no auxílio ao exercício do controle social sobre a administração pública (Tese de Doutorado). São Paulo, SP: Fundação Getulio Vargas.

Roulston, K. (2014). Analysing interviews. In U. Flick (Ed.), The SAGE handbook of qualitative data analysis (pp. 297-312). Thousand Oaks, CA: SAGE.

Schreier, M. (2014). Qualitative content analysis. In U. Flick (Ed.), The SAGE handbook of qualitative data analysis (pp. 170-183). Thousand Oaks, CA: SAGE.
Speck, B. W. (2011). Auditing institutions. In T. Power, \& M. Taylor (Eds.), Corruption and democracy in Brazil: the struggle for accountability (pp. 127-161). Notre Dame, IN: University of Notre Dame Press.

Spence, C., \& Carter, C. (2014). An exploration of the professional habitus in Big-4 accounting firms. Work, Employment and Society, 28, 946-962.

Stapenhurst, R., \& Titsworth, J. (2001). Features and functions of supreme audit institutions (World Bank PREM Note 59). Washington, DC: The World Bank.

Sugden, J., \& Tomlinson, A. (2017). Football, corruption and lies: revisiting 'Badfellas', the book FIFA tried to ban. London, England: Routledge.

Teixeira, M. A. (2017). Os tribunais de contas brasileiros e o controle dos controladores. In M. A. Alves, J. I. M. Brigagão, \& F. Burgos (Eds.), Por uma gestão pública democrática: 25 anos do Centro de Estudos em Administração Pública e Governo (pp. 203-218). São Paulo, SP: FGV EAESP.

Thornberg R., \& Charmaz, K. (2014). Grounded theory and theoretical coding. In U. Flick (Ed.), The SAGE handbook of qualitative data analysis (pp. 153169). Thousand Oaks, CA: SAGE.

Thornton P. H., Ocasio W., \& Lounsbury M. (2012). The institutional logics perspective: a new approach to culture, structure and process. Oxford, England: Oxford University Press.

Veja. (2008, 2 de julho). Compraram o tribunal: documentos revelam que conselheiros do TCE do Rio de Janeiro vendiam decisões a prefeituras. Recuperado de https://veja.abril.com.br/blog/reinaldo/veja-48211-querida-comprei-um-tribunal/

Willeman, M. M. (2016). O desenho institucional dos tribunais de contas e sua vocação para a tutela da accountability democrática: perspectivas em prol do direito à boa administração pública no Brasil. Rio de Janeiro, RJ: Ed. PUC-Rio.

Yin, R. K. (2009). Case study research: design and methods (4th ed.). Thousand Oaks, CA: SAGE.

Zald, M. N., \& Lounsbury, M. (2010). The wizards of Oz: Towards an institutional approach to elites, expertise and command posts. Organization studies, 31(7), 963-996. 
RAP | Práticas não adequadas nos tribunais de contas

\section{André Feliciano Lino}

https://orcid.org/0000-0003-1121-4971

Doutor em Controladoria e Contabilidade; Professor na Faculdade de Ciências Contábeis da Universidade Federal do Pará (Facicon/UFPA). E-mail: aflino@ufpa.br

\section{André Carlos Busanelli de Aquino}

https://orcid.org/0000-0002-0329-410X

Doutor em Ciências Contábeis; Professor Titular da Universidade de São Paulo (USP).E-mail: aaquino@usp.br 